\title{
A responsabilidade do Estado pela prestação jurisdicional em face do ordenamento jurídico brasileiro ${ }^{1}$
}

\author{
Gisandro Carlos Julio ${ }^{2}$ \\ Marlene Kempfer Bassoli ${ }^{3}$
}

\begin{abstract}
Resumo
Busca compreender o instituto da responsabilidade do Estado no seu aspecto geral e, particularmente, no tocante ao exercício da função jurisdicional, tendo por diretrizes o desenvolvimento histórico e as teorias informadoras da responsabilidade do Estado-jurisdição. Visa despertar o entendimento do serviço judiciário como espécie do serviço público em geral e, do mesmo modo, demonstrar o enquadramento do magistrado na categoria de agente público. Analisa o ordenamento jurídico, buscando absorver as várias formas pelas quais se apresenta a atividade judiciária danosa. Analisa o Texto Constitucional, com vistas ao entendimento das características da responsabilização do Estado-Juiz. Indica a consagração da responsabilidade do Estado pela prestação jurisdicional, delimitando a sua aplicabilidade e teoria informadora.
\end{abstract}

Palavras-Chave: Responsabilidade; Judiciário; Serviço Público; Agente Público; Atividade Judiciária Danosa.

\section{Introdução}

Hodiernamente, vivencia-se o acentuamento da complexidade das relações intersubjetivas e o alargamento das situações conflituosas surgidas no seio da sociedade, o que reclamada a existência de mecanismos de controle social e de formas eficazes de solução de conflitos.

Em face do art. 5ㅇ, XXXV, da Constituição Federal, que consagra o princípio da inafastabilidade da apreciação jurisdicional, observa-se que o Estado avocou para si em caráter exclusivo a prerrogativa de dizer o direito ao caso concreto.

Diante desse panorama, surge o questionamento acerca da possibilidade de responsabilização do Estado pela prestação jurisdicional danosa, ou seja, pela causação

1 Este ensaio teve por referência Trabalho de Conclusão de Curso apresentado ao Curso de Direito da Universidade Estadual de Londrina, de autoria do primeiro sob a orientação da segunda.

Aluno do 5o ano de Direito da Universidade Estadual de Londrina.

3 Doutora em Direito do Estado - Direito Tributário pela PUC-SP. Professora de Direito Tributário na graduação do Curso de Direito da Universidade Estadual de Londrina e dos programas de Mestrado em Direito da Universidade Estadual de Londrina e da Universidade de Marília. 
estatal de danos à esfera de direitos juridicamente protegida dos jurisdicionados, seja pela ausência de atuação jurisdicional, seja pela morosidade na sua prestação, seja ainda, pela atuação dolosa ou culposa do magistrado.

Vislumbra-se que o presente tema ainda representa terreno movediço em face da discrepância entre doutrina e jurisprudência acerca da consagração da responsabilidade estatal. Sabedores da falibilidade dos agentes públicos incumbidos da prestação jurisdicional e verificada a necessidade de um órgão judiciário atuante e célere, avulta em importância a delimitação das linhas mestras no concernente à Responsabilidade do Estado pela Prestação Jurisdicional em face do Ordenamento Jurídico Brasileiro.

\section{Conceito de responsabilidade do Estado}

A responsabilidade do Estado deve ser compreendida como sendo a vinculação deste ente público ao dever jurídico de reparar os danos causados por seus agentes à esfera juridicamente protegida dos indivíduos.

Conforme enuncia o dispositivo fundamental no concernente ao assunto tratado, “as pessoas jurídicas de direito público [...] prestadoras de serviço público responderão pelos danos que seus agentes, nessa qualidade, causaram a terceiros, assegurado o direito de regresso contra o responsável nos casos de dolo ou culpa" (art. 37, §6으, Constituição Federal).

O Professor Celso Antonio Bandeira de Mello assim se manifesta acerca do entendimento do instituto da Responsabilidade do Estado:

Entende-se por responsabilidade patrimonial extracontratual do Estado a obrigação que lhe incumbe de reparar economicamente os danos lesivos à esfera juridicamente garantida de outrem e que lhe sejam imputáveis em decorrência de comportamentos unilaterais, lícitos ou ilícitos, comissivos ou omissivos, materiais ou jurídicos. (2004, p. 876).

Diante da concepção de um Estado de Direito albergado pela Constituição Federal de 1988, imperativa a responsabilização do Estado por comportamentos lesivos à esfera de atuação dos particulares, até mesmo quando lícitos, quando o indivíduo não tenha a obrigação de suportar referido encargo. 


\section{Breve histórico da responsabilidade do Estado}

O posicionamento do instituto da responsabilidade do Estado nos dias atuais representa um panorama de sua evolução no decorrer da história, partindo de um período de completa irresponsabilidade, passando por momentos em que predominavam as noções civilistas de responsabilidade e atracando, hodiernamente, no porto dos conceitos publicistas de responsabilização do Estado.

O período de irresponsabilidade do Estado compreende o momento em que vigoravam os regimes absolutistas e despóticos, em que o Rei soberano detinha um poder supremo, oriundo de Deus e que, por isso mesmo, não haveria de se conceber sua responsabilização diante de eventos danosos. Ademais, a noção de soberania, carregada com a premissa de poder ilimitado dava a tônica do momento em que se situavam as idéias acerca do instituto em pauta.

Amparados nas lições do Professor Carlos Ari Sundfeld, pode-se entender que:

O poder soberano não encontra limitação, quer interna, quer externa. Será, por isso, insuscetível de qualquer controle. Parecia, ao espírito da época, que quem detinha o poder - de impor normas, de julgar, de administrar - não poderia ser pessoalmente sujeito a ele: ninguém pode estar obrigado a obedecer a si próprio (grifos acrescidos) (2002 p. 34).

Convém salientar que são deste momento histórico as máximas the king can do no wrong (o rei não pode errar) e quod principi placuit legis habet vigorem (aquilo que agrada ao príncipe tem força de lei).

Num segundo momento da evolução do instituto sub examine destaca-se a noção civilista de responsabilização, em que o indivíduo deveria provar que o agente público obrou com culpa ou dolo na implementação do evento lesivo. Nesta fase, convém salientar a cisão dos comportamentos estatais em Atos de império e Atos de gestão. Naqueles, o Estado estaria manifestando a vontade pública, de modo que se deveria afastar a responsabilização do ente estatal, por estar em conformidade com a vontade geral.

De outra feita, diante dos Atos de gestão, o Estado atuaria como um particular, de forma que deveria responder pelos danos suportados pelos indivíduos quando fosse verificada ao menos a culpa do agente público causador do dano. Como se observa, a teoria 
em pauta provoca grandes dissabores ao indivíduo que tem o ônus de provar que o agente público obrou com culpa lato sensu.

Com o desenvolvimento do instituto da responsabilidade do Estado, passase à implementação das noções de Direito Público, o que faz emergir o estudo das teorias da Falta do Serviço ou Culpa Administrativa e teoria do Risco Administrativo.

A teoria da Culpa Administrativa, não obstante ainda exija muito do administrado, representou um avanço no estudo da responsabilidade estatal, visto que o lesado deve provar uma culpa especial da administração pública. Nesse estágio evolutivo não se cogita de culpa ou dolo do agente público, mas tão somente da inexistência ou deficiência do serviço público prestado, verificável nas hipóteses de inexistência do serviço público (culpa in omittendo), mau funcionamento do serviço (culpa in comittendo) ou retardamento na realização do serviço público.

Conforme esclarece Augusto do Amaral Dergint:

A 'falta do serviço' (como também convencionou-se traduzir a locução faute Du service) geralmente relaciona-se com um ato ilícito de um agente público, mas sua noção abarca ainda as 'faltas anônimas', em que não se identifica um agente certo: a culpa administrativa é do próprio serviço público, que, funcionando inadequadamente produz um dano (1994, p. 40, grifos do autor).

A responsabilidade defendida por essa teoria é eminentemente subjetiva, pois exige que o indivíduo indique o elemento culpa, não obstante diante da "culpa anônima" do serviço público a presunção se faça presente, o que não elide o seu caráter subjetivo.

A teoria do Risco Administrativo abarca as hipóteses de prestação de serviços públicos passíveis de causarem danos à esfera de atuação dos particulares, o que traz a baila o entendimento de que, para a responsabilização estatal, basta a verificação do nexo de causalidade entre o dano e o funcionamento do serviço público. Aqui, avulta em importância a noção de solidariedade social, visto que se toda a sociedade usufrui as benesses dos serviços prestados, nada mais justo que seja dividido entre todos o prejuízo suportado por um indivíduo isoladamente.

Oreste Nestor de Souza Laspro aduz que nesta fase publicista "surge a teoria do risco, segundo a qual, partindo do pressuposto de que o Estado age em benefício de todos, é natural que todos tenham que repartir eventual prejuízo sofrido por algum" (2000, p. 72). 
Dessa forma, verificado o nexo de causalidade entre o evento lesivo e a ação ou omissão estatal, avulta em importância a necessidade de responsabilização do Estado, restando a este, para se eximir, a indicação de alguma excludente como a culpa da vítima.

\section{Responsabilidade do Estado pela prestação jurisdicional}

A Responsabilidade do Estado pela prestação jurisdicional compreende o entendimento de que, avocando para si a prerrogativa de dizer o direito ao caso concreto, em face do art. 50, XXXV, da Constituição Federal, o Estado tem o dever jurídico de suportar os encargos advindos da atuação lesiva de seus agentes, quando da manifestação jurisdicional por meio de sentenças, despachos ou decisões interlocutórias (art. 162, CPC). Assim, “justamente, por ser uma pessoa jurídica (de Direito Público), o Estado possui aptidão tanto para adquirir direitos quanto para contrair obrigações" (DERGINT, 1994, p. 34), o que corrobora a compreensão de que o referido ente deva suportar os prejuízos que "seus agentes, nessa qualidade, causaram a terceiros, assegurado o direito de regresso contra o responsável nos casos de dolo ou culpa" (art. 37, §6으, da Constituição Federal).

Diante da divergência existente entre doutrina e jurisprudência, faz-se necessária uma análise das teorias informadoras da responsabilidade do Estado-Juiz, com vistas ao delineamento de seu sentido e alcance.

\section{Teorias acerca da responsabilidade do Estado-juiz}

\subsection{Teoria da irresponsabilidade}

A Responsabilização do Estado pela Prestação Jurisdicional representa um dos últimos redutos, ao lado da responsabilidade por atos legislativos, em que a jurisprudência ainda se encontra leniente na aceitação, em face de argumentos inconsistentes como a inexistência de lei específica, a independência dos magistrados, a soberania do Poder Judiciário e a incontratabilidade da coisa julgada.

Contudo, como se verá a seu tempo, referidos argumentos destoam do espírito do Texto Constitucional diante de sua patente incoerência, vez que a Constituição Federal alberga em seu Art. 37, §6ㅇ a responsabilização direta e objetiva do Estado. 
Um dos argumentos aventados para a irresponsabilidade estatal na seara aqui enfocada refere-se à pretensa inexistência de lei específica determinando a responsabilização do Estado. Em face disso, o Estado somente responderia diante do erro judiciário penal, previsto no art. 5ำ, LXXV, da Constituição Federal e Art. 630 do Código de Processo Penal, restando todas as demais hipóteses de atuação estatal danosa alheias ao instituto da responsabilidade.

O argumento da inexistência de lei específica não encontra respaldo jurídico, vez que, não obstante represente princípio geral de direito a obrigação imposta àquele que cause dano à esfera juridicamente protegida de outrem de reparar a situação lesiva por ele gerada, o Texto Constitucional alberga de forma indubitável a responsabilidade direta e objetiva do Estado pela atuação lesiva de seus agentes.

No que tange ao argumento da independência dos magistrados, também não configura fundamento sólido para se afastar a responsabilização estatal, já que o próprio Texto Constitucional prevê garantias para a atuação desses agentes, com vistas à promoção de sua liberdade de consciência e apreciação. Ademais, o art. 37, §6o , da CF, prevê a responsabilização direta e objetiva do Estado, restando a este o direito de regresso em face do agente público causador do dano, somente diante de dolo ou culpa.

Conforme nos elucida Lair da Silva Loureiro Filho:

A responsabilidade por atividade judiciária não priva o julgador da livre apreciação das provas, nem restringe sua liberdade de consciência, possibilitando-lhe a liberdade na escolha do conteúdo da decisão, desde que motivada e amparada nos limites do ordenamento jurídico vigente (da mesma forma que a responsabilidade pública não constitui freio ou óbice à administração) (2005, p. 114).

O argumento da soberania do Poder Judiciário é tão inconsistente quanto os demais, visto que soberano mesmo é o Estado em sua unicidade, sendo o Poder Judiciário, o Poder Legislativo e o Poder Executivo, apenas autônomos, uns em relação aos outros, não sendo cabível o entendimento de, com ser a função jurisdicional uma das funções do Estado, como também o são as demais, seja elevada à posição de soberana.

Na labuta pelo esclarecimento dos frágeis argumentos embasadores da teoria que defende a irresponsabilidade estatal pela prestação jurisdicional danosa, convém tecer breves comentários no que tange ao fundamento da Coisa Julgada. 
Nesse sentido, certa corrente jurisprudencial defende a irresponsabilidade do Estado com base no entendimento de que a responsabilização pela prestação jurisdicional afrontaria o instituto da Coisa Julgada. Contudo, há de se frisar o caráter relativo desse instituto, vez que o próprio ordenamento jurídico prevê hipóteses de desfazimento do julgado, seja pela ação rescisória (Art. 485, CPC), no cível, seja pelo instituto da revisão criminal (Arts. 621 e ss. do CPP), no crime, não obstante restarem diversos outros atos incólumes à Coisa Julgada.

Questão que se impõe é a de se esclarecer sobre a necessidade de desfazimento da coisa julgada para se pleitear a reparação pelos danos advindos da atuação jurisdicional.

Em um primeiro instante, cabe salientar que se ainda não se implementou o instituto da Coisa Julgada não há de se falar em responsabilização de danos por parte do Estado, visto que o jurisdicionado tem a sua disposição os mecanismos jurídicos para a busca da verdade real e formal.

Quando já se tenha verificada a estabilização dos litígios pela Coisa Julgada, mas ainda não tenha transcorrido o prazo decadencial de dois anos 'para propositura da rescisória, tem o jurisdicionado a possibilidade de se utilizar do mecanismo devido, com o fito de desconstituir a decisão transitada em Julgado, ou a qualquer momento propor a revisão criminal, e aí, sendo procedente, promover a ação de reparação de danos em face do Estado.

Não obstante os esclarecimentos retro expendidos comunga-se do entendimento de que, mesmo diante de coisa soberanamente julgada, ou seja, quando já tenha esgotado o prazo decadencial de dois anos para a propositura da rescisória, tem o jurisdicionado a seu talante a possibilidade de obter a reparação de danos, visto que a coisa julgada e a reparatória emergem situações diversas, pois "a lide é outra, não havendo coisa julgada entre lesado e o Estado, pois tal pretensão não foi julgada, sendo outras as partes, outra a causa de pedir e outro o pedido" (SERRANO JUNIOR, 1996, p. 139). Ademais, assim agindo, estar-se-á dando maior primazia ao valor justiça, não obstante seja também medida fundamentada por princípios basilares do direito. 


\section{Teoria da responsabilidade do Estado-juiz}

Após a análise dos fundamentos mais importantes levantados pela corrente que defende a irresponsabilidade do Estado pela prestação jurisdicional danosa, cumpre assinalar que o Texto Constitucional alberga no art. 37 , §6 a responsabilização direta e objetiva do Estado, o que ocorreu pela primeira vez na Constituição Federal de 1946, desenvolvendo-se e chegando até os dias atuais.

A responsabilidade objetiva do Estado, na modalidade do risco administrativo, ou seja, adequado às situações em que a atuação proporcione risco de danos, impõe-se diante da grandiosidade de situações em que o Estado-juiz possa causar lesões à esfera juridicamente protegida dos jurisdicionados.

Sabendo-se que se está diante de uma República, o que denota a necessária responsabilização dos agentes públicos, e que esta representa um Estado de Direito, imperativa se torna a submissão do Estado e dos magistrados (agentes públicos) aos ditames da lei, vale dizer mais, da Constituição Federal.

“Atualmente vige o princípio da responsabilidade objetiva do Estado, decorrente de disposição constitucional, entretanto nem sempre foi assim, passando-se ao longo dos anos por uma vagarosa evolução dessa responsabilidade" (NANNI, 1999, p. 97).

$\mathrm{O}$ art. 37, $\S 60$, da $\mathrm{CF}$, determina que o Estado será responsável pelos danos ocasionados por seus agentes, restando o direito de regresso quando estes tenham atuado com dolo ou culpa.

Conforme nos elucida a questão, convém trazer a lume as lições do Prof. Giovanni Ettore Nanni:

\footnotetext{
Parece-nos justamente que com a adoção pelo legislador constituinte da responsabilidade objetiva, deve-se perquirir o nexo de causalidade entre o dano sofrido e a ação causadora do dano, ou seja, se houver uma relação de causa e efeito entre a atividade do agente público e o dano, este deverá ser reparado; por outro lado, ausente essa relação de causalidade, não há que se falar em responsabilidade objetiva do Estado (1999, p. 102).
}

Dessa forma, sendo o magistrado um agente público e o serviço judiciário espécie de serviço público (como se demonstrará), há de se entender a situação subsumida ao regramento contido no Texto Constitucional (art. 37, § 6ㅇ), de modo que verificada a relação 
de causalidade entre o dano suportado pelo jurisdicionado e a atuação jurisdicional, in continenti, avulta a responsabilização objetiva do Estado pela prestação jurisdicional, na modalidade do risco administrativo.

\section{Atividade judiciária: serviço público}

A jurisdição compreende uma das funções do Estado, pela qual este avocou para si a prerrogativa de fazer atuar o direito ao caso concreto, em face do que salienta o art. 5ㅇ, XXXV, da Carta Magna, o que faz crer seja a prestação jurisdicional verdadeira prestação de serviço público.

O termo atividade judiciária refere-se a todas as atividades prestadas pelo Poder Judiciário, abarcando tanto as atividades meramente administrativas (nomeações, concessão de férias etc), como as atividades tipicamente jurisdicionais de fazer atuar o direito ao caso concreto.

Nas lições do Prof. Lair da Silva Loureiro Filho:

Considera-se a atividade jurisdicional como espécie da atividade judiciária. Esta, por sua vez, abrange todos os atos praticados por agentes do Poder Judiciário. Desta forma, serão judiciários os atos dos juízes no exercício de atividade estritamente jurisdicional (de sua competência exclusiva), contenciosa ou voluntária, bem como aqueles por eles praticados como administradores, consubstanciados nos atos materialmente administrativos. Somam-se a estes os atos praticados por servidores do Poder Judiciário, por seus colaboradores a qualquer título, a demora excessiva na prestação jurisdicional, a falha do serviço, anônima ou não (2005, p. 82).

Sabendo-se que as atividades desenvolvidas pelo Estado com vistas à promoção de utilidade e benesses aos indivíduos configuram serviço público, há de se entender seja a jurisdição serviço eminentemente público e o magistrado, agente público em sentido amplo, pois investido em cargo criado por lei e regido por normas de direito público. Juary C. Silva apud Dergint assim se expressa:

Efetivamente, aceito que o Estado, no desempenho da função jurisdicional, desenvolve um serviço público - o que temos por irrecusável e óbvio depreendese que o Estado-jurisdição é tão responsável pelos seus atos lesivos, quanto o é, no respeitante aos seus, o Estado-Administração. Realmente, todo o serviço público implica a idéia de responsabilidade de quem o executa, em qualquer modalidade, em face da jurisdicização da atividade estatal e da submissão 
do Estado ao Direito, nos moldes do constitucionalismo subseqüente à Revolução Francesa (1994, p. 114-115).

Como se observa, com ser a atividade jurisdicional prestação de serviço eminentemente público, já que tem por intuito a pacificação dos conflitos intersubjetivos, há de se compreender o magistrado como sendo, de fato, um agente público, nos moldes do preceituado no art. $37, \S 6$, do Texto Constitucional.

Edmir Netto de Araújo apud Lair da Silva Loureiro faz a seguinte elucidação sobre o assunto ora tratado, com o fim de pôr uma pedra sobre o questionamento acerca do enquadramento dos magistrados no rol dos agentes públicos, em vista de quatro requisitos quais sejam: “a) a titularidade de um cargo criado por lei; b) investidura legal, por autoridade competente em caráter permanente; c) incorporação, mediante posse, compromisso e efetivo exercício; d) sujeição a regime jurídico de direito público" (2005, p. 108).

\section{Atividade judiciária danosa}

A partir do art. 5ㅇ, XXXV, da Constituição Federal, observa-se que o Estado avocou para si a prerrogativa de dizer o direito aos conflitos intersubjetivos surgidos no meio social com vistas à pacificação.

Assim, quando se fala em atividade judiciária danosa deve-se compreender todas as atividades do Poder Judiciário passíveis de ocasionar lesões aos indivíduos, sejam atividades meramente administrativas, sejam aquelas atividades jurisdicionais propriamente ditas praticadas por magistrados no exercício de sua função típica de fazer atuar o direito.

A responsabilização do Estado-juiz pode se dar tanto por atos lícitos quanto por atos ilícitos. Na categoria dos atos lícitos, encontram-se aquelas hipóteses em que o Estado atua em conformidade com os estritos termos das normas estabelecidas in casu, todavia, ensejadoras de prejuízos desproporcionais ao sacrifício esperado, o que configura sua anormalidade. Desse modo, são requisitos para a configuração do dano indenizável por ato lícito a anormalidade e a especialidade. Por anormalidade se entende o prejuízo superior ao dano esperado, ao passo que especial é o dano que atinge um certo jurisdicionado, especificamente (LOUREIRO FILHO, 2005, p. 228).

Por outro lado, os atos ilícitos são aqueles que de alguma forma são praticados em desconformidade com as normas estabelecidas pelo ordenamento jurídico. 
No presente estudo, dar-se-á cabo de apenas algumas hipóteses de atividade jurisdicional danosa, quais sejam o erro judiciário (penal e civil), denegação de justiça e a demora injustificada na prestação jurisdicional.

\subsection{Erro judiciário}

O erro judiciário compreende a prestação jurisdicional danosa que ocorre quando da atuação equivocada do agente público, seja por meio de sentença, despachos ou decisões interlocutórios (art. 162, do Código de Processo Civil). Representa, na acurada análise do Prof. Oreste Nestor de Souza Laspro, "todo ato jurisdicional que, seja pelo mal enquadramento dos fatos ao mundo do direito, seja pela errônea aplicação das normas, viola regras de natureza processual e material, em qualquer dos ramo do direito" (2000, p. 223), ou seja, pode ser visualizado como sendo qualquer equívoco ou vício na manifestação volitiva do magistrado, seja decorrente de culpa, de erro (de fato ou de direito), seja pela ignorância do magistrado passível de causação de danos.

Compreende, portanto, uma das formas mais comuns de causação de danos aos jurisdicionados, concernente no equívoco na manisfestação volitiva do magistrado, verificável também, pelo error in procedendo (equívoco na condução do procedimento) e no error in judicando (equívoco no julgamento propriamente dito).

O erro judiciário penal é o que provoca maiores prejuízos aos jurisdicionados, pois afeta bens jurídicos de grande relevância como a vida, a honra, dentre outros. Nesse âmbito, pode-se mencionar como hipóteses de ocorrência de erro judiciário a situação de decretação de prisão provisória ou processual (prisão em flagrante, prisão preventiva, prisão resultante de sentença recorrível e prisão temporária) que ao depois venha a ser verificada a inocência do jurisdicionado. Mesmo que sejam verificados todos os pressupostos de sua decretação, venha ao final o decreto de inocência do jurisdicionado, há de se favorecê-lo com a reparação devida.

Também no âmbito civil deve-se entender possível a existência de danos aos jurisdicionados, não obstante sejam os bens jurídicos penais de maior relevo, face ao que preceitua genericamente o art. 5ํ, LXXV, CF : “O Estado indenizará o condenado por erro juridiciário $[\ldots]^{\prime \prime}$. 


\subsection{Denegação de justiça}

A Constituição Federal, em seu art. 5, XXXV, prevê o princípio da inafastabilidade do controle jurisdicional, quando determina que "a lei não excluirá da apreciação do Poder Judiciário lesão ou ameaça a direito", o que faz supor que o jurisdicionado possui o direito e a garantia de que sua demanda será apreciada, ou seja, que ser-Ihe-á concedida a tutela jurisdicional. Desse modo, o Estado deverá proporcionar aos indivíduos a tutela dos conflitos intersubjetivos em que se encontram envolvidos, sob pena de se configurar lesão passível de reparação por parte deste ente público.

A denegação de justiça, portanto, configura a completa ausência de prestação da tutela jurisdicional, seja pelo inadequado aparelhamento do Poder judiciário, seja por falta atribuível ao próprio magistrado, agente público incumbido de exercer a tutela jurisdicional (DERGINT, 1994, p. 189-193).

Pode-se entender a expressão denegação de justiça sob dois aspectos: lato sensu e stricto sensu. Naquele, a denegação de justiça advém de uma deficiência na estrutura do órgão jurisdicional, acarretando, de conseqüência, a ausência da prestação jurisdicional. Já a denegação de justiça vista de um quadrante estrito representa a própria negação do Estadojurisdição em promover a proteção ao direito lesado (DERGINT, 1994, p. 189-193).

Como se observa, a ausência de prestação jurisdicional representa uma das formas mais graves de lesão aos direitos dos jurisdicionados, pois não obstante tenha o ordenamento jurídico determinado a inafastabilidade da prestação jurisdicional, previu mecanismos para que tal desiderato seja desincumbido a contento, quando determina no art. 126, do CPC, que "o juiz não se exime de sentenciar ou despachar alegando lacuna ou obscuridade da lei. No julgamento da lide caber-lhe-á aplicar as normas legais; não as havendo, recorrerá à analogia, aos costumes e aos princípios gerais de direito".

\subsection{Demora excessiva na prestação da tutela jurisdicional}

A sociedade hodierna apresenta relações humanas cada vez mais complexas, conflitos que exigem a cada dia uma manifestação atuante, dinâmica e célere do magistrado, de modo que o conflito de interesses seja resolvido num prazo razoável. 
Desse modo, quando se fala em demora excessiva na prestação da tutela jurisdicional fala-se propriamente no anormal funcionamento do serviço jurisdicional, ou seja, "significa examinar aquelas hipóteses em que o Estado deixa de prestar, total ou parcialmente, o serviço jurisdicional" (LASPRO, 2000, p. 226-227).

O Texto Constitucional em seu art. 5ㅇ, XXXV, afirma que "a lei não excluirá da apreciação do Poder Judiciário lesão ou ameaça a direito", o que se deve entender, por se tratar de direito e garantia dos indivíduos, que estes quando propõem ao órgão jurisdicional a apreciação do conflito intersubjetivo, buscam não apenas o acesso ao judiciário, mas efetivamente o acesso à justiça.

Ada Pelegrini Grinover apud Jorge de Oliveira Vargas pontifica que:

Acesso à justiça, longe de confundir-se com acesso ao judiciário significa algo mais profundo, pois importa no acesso ao justo processo, como um conjunto de garantias capaz de transformar o mero procedimento em um processo tal, que viabilize concretamente e efetivamente a tutela jurisdicional $(1999$, p. 47 , grifo do autor).

Em vista desta plêiade de idéias, impõe-se admitir que o jurisdicionado quando se volta ao Estado-Jurisdição, procura, além de uma justa composição do litígio, que esta se realize num prazo razoável, ou pelo menos, dentro em certos limites, já que "justiça que tarda é falha e justiça desacreditada enseja a proliferação de formas paralelas de realização privada de solução de litígios, nunca circunscritas ao império do Estado de Direito" (LOUREIRO FILHO, 2005, p. 211). Encontra-se, aqui, portanto, configurada a responsabilização estatal por comportamentos omissivos ilícitos, o que se compreende com base na sempre acurada doutrina do Prof. Paulo Modesto:

\footnotetext{
A responsabilidade por omissão traduz modalidade de responsabilidade por comportamento ilícito, uma vez que a omissão causadora de dano é apenas aquela violadora de normas exigentes de ação ou impositivas de um dever de cuidado por parte dos poderes públicos (Revista Diálogo Jurídico).
}

A par disso, para a configuração da responsabilidade estatal pela demora na prestação da tutela jurisdicional, imperativo se torna encontrar uma delimitação para o que seja demora justificável e demora excessiva na prestação. Nesse sentido, entende-se que, não obstante os prazos processuais sejam indicativos da referida demora, cabe ao 
magistrado dirigir os processos com diligência, deitando seu bom-senso na análise das situações morosas no intuito de verificar a excessividade na entrega da tutela jurisdicional.

Verificado que seja o nexo de causalidade entre a demora excessiva da prestação jurisdicional e o dano material e/ou moral suportado pelo lesado, in continenti, avulta a vinculação do Estado ao dever reparatório, em face da consagração pelo art. $37, \S^{6}$ 으, da Constituição Federal, da responsabilidade direta e objetiva do Estado, na modalidade do risco administrativo.

Com efeito, não encontra guarida no ordenamento jurídico o entendimento no sentido de que a omissão antijurídica aqui perpetrada seria reparável somente com base em responsabilidade subjetiva, na modalidade da teoria da faute du service, visto que além de contrariar preceito constitucional (art. $37, \S^{\circ}$ ) ) determinante da responsabilidade objetiva, acarretaria ao lesado pesados ônus, visto que deveria provar a culpa anônima ou especial do órgão estatal.

\section{Conclusão}

A responsabilidade do Estado tratada pelo art. 37, §6ㅇ da Constituição Federal trouxe para o jurisdicionado, como confirmação das diretrizes historicamente consagradas desde a Constituição de 1946, o direito e a garantia de não ser lesado em sua esfera de direitos juridicamente protegidos. E mais, se porventura essa irregularidade venha ocorrer, tem o administrado em suas mãos mecanismos juridicamente hábeis a ensejar a reparabilidade de uma situação deveras insustentável, em face da consagração de um Estado Democrático de Direito.

No presente estudo, procurou-se abordar o entendimento da responsabilidade do Estado, em seu aspecto geral, delineando o desenvolvimento histórico por que passou referido instituto, de modo a trazer subsídios à compreensão do tema específico deste trabalho.

A par disso, desenvolveu-se um estudo da responsabilidade do Estado pela Prestação jurisdicional, demonstrando os frágeis argumentos de uma teoria que defende a irresponsabilidade estatal nessa seara.

No desenvolvimento, percebeu-se a discrepância entre doutrina e jurisprudência, visto que esta ainda se baseia em teorias destoantes do ordenamento jurídico. 


\section{A responsabilidade do Estado pela prestação jurisdicional em face do ordenamento jurídico}

brasileiro

Tendo em vista o dispositivo fundamental constante do art. 37, §6 da Constituição Federal, verifica-se que o legislador consagrou a responsabilidade direta e objetiva do Estado pela prestação jurisdicional danosa, seja por ação seja por omissão, seja por ato lícito seja por ato ilícito do agente público, restando ao Estado- jurisdição o direito de regresso para haver do magistrado causador da lesão o que houver despendido, desde que tenha este atuado com dolo ou culpa.

Assim, não há de se dar guarida a dispositivos infraconstitucionais que determinam a responsabilidade direta do magistrado, nem tampouco entendimentos jurisprudenciais que consagram a responsabilidade concorrente entre Estado e agente público, visto que o Texto Constitucional determina de modo indubitável a responsabilidade estatal direta e objetiva, na modalidade do risco administrativo.

\section{Referências}

ANDRIGHI, Fátima Nancy. A Responsabilidade do Estado pela Violação do Direito à Justiça num Prazo Razoável. Disponível em: <http:// bdjur.stj.gov.br/dspace/handle/2011/637>. Acesso em: 19 maio 2006.

BASTOS, Celso Ribeiro. Curso de Direito Constitucional. 19. ed. São Paulo: Saraiva, 1998.

CAPPELLETTI, Mauro. Juízes Irresponsáveis? .Porto Alegre: Sergio Antonio Fabris Editor, 1989.

CAPEZ, Fernando. Curso de Processo Penal. 12. ed. São Paulo: Saraiva, 2005.

CINTRA, Antônio Carlos de Araújo. Grinover, Ada Pelegrini. Dinamarco, Cândido Rangel. Teoria Geral do Processo. 19. ed. São Paulo: Malheiros, 2003.

DERGINT, Augusto do Amaral. Responsabilidade do Estado por Atos Judiciais. São Paulo: Revista dos Tribunais, 1994.

DI PIETRO, Maria Sylvia Zanella. Direito Administrativo. 17. ed. São Paulo: Atlas, 2004.

DINIZ, Maria Helena. Curso de Direito Civil Brasileiro. Responsabilidade Civil. 16. ed. São Paulo: Saraiva, 2002. v. 7.

FACHIN, Zulmar. Responsabilidade Patrimonial do Estado por Ato Jurisdicional. Rio de Janeiro: Renovar, 2001. 
FIGUEIREDO, Lúcia Valle. Curso de Direito Administrativo. 6. ed. São Paulo: Malheiros, 2003.

LOUREIRO FILHO, Lair da Silva. Responsabilidade Pública por Atividade Judiciária. De acordo com a EC n. 45/2004 - Reforma do Judiciário. São Paulo: Editora Revista dos Tribunais, 2005.

HENTZ, Luiz Antonio Soares. Direito Administrativo e Judiciário. São Paulo: Leud, 1998.

JÚNIOR TEODORO, Humberto. Curso de Direito Processual Civil. 41. ed. Rio de Janeiro: Forense, 2004. v. 1.

LASPRO, Oreste Nestor de Souza. A Responsabilidade Civil do Juiz. São Paulo: Revista dos Tribunais, 2000.

MEIRELLES, Hely Lopes. Direito Administrativo Brasileiro. 29. ed. São Paulo: Malheiros, 2004.

MELLO, Celso Antonio Bandeira de. Curso de Direito Administrativo. 17. ed. São Paulo: Malheiros, 2004.

MODESTO, Paulo. Responsabilidade do Estado pela Demora na Prestação jurisdicional. Revista Diálogo Jurídico, Salvador, v. 1, n. 1, 2001. Disponível em:

$<$ http://www.direitopublico.com.br/pdf/REVISTADIALOGO- JURIDICO-01-2001-PAULOMODESTO.pdf>. Acesso em: 23 abr. 2006.

MORAES, Alexandre de. Direito Constitucional Administrativo. São Paulo : Atlas, 2002.

NANNI, Giovanni Ettore. A Responsabilidade Civil do Juiz. São Paulo: Editora Max Limonad, 1999.

SERRANO JUNIOR, Odoné. Responsabilidade Civil do Estado por Atos Judiciais. Curitiba: Juruá, 1996.

SILVA, José Afonso da. Curso de Direito Constitucional Positivo. 22. ed. São Paulo: Malheiros, 2003.

SUNDFELD, Carlos Ari. Fundamentos de Direito Público. 4. ed. São Paulo: Malheiros, 2002.

VARGAS, Jorge de Oliveira. Responsabilidade Civil do Estado pela Demora na Prestação da Tutela Jurisdicional. Curitiba: Juruá, 2001.

WAMBIER, Luiz Rodrigues; ALMEIDA, Flávio Renato Correia de; TALAMINI, Eduardo. Curso Avançado de Direito Processual Civil: Teoria Geral do Processo e Processo de Conhecimento. 6. ed. São Paulo: Revista dos Tribunais, 2003. v. 1. 